\title{
Wind force components on low-rise building models and flow fields
}

\author{
Hirotoshi Kikuchi, Yukio Tamura and Kazuki Hibi
}

\begin{abstract}
In this paper, fluctuating surface pressure measurements are made for four flat roofed building models with square or rectangular plans in order to examine wind load combinations. The fluctuating pressures are integrated over all their surfaces and 'results are obtained as along-wind force, crosswind force, vertical force and torsional moment on their frames. The maximum wind force in consideration of the wind direction component and other simultaneously observed wind force components are examined, and some interesting facts regarding the wind force combinations are discussed on the basis of absolute value correlations, phase-plane expressions and so on. This investigation concurrently measured wind pressure applied to a wall surface and the resulting wind flow field around the building using a wind pressure model and DPIV systems. Data obtained through the measurements enabled identification of the wind flow field around the building that results from the maximum and minimum wind force applied to it.
\end{abstract}

Keywords: Low-rise building, Wind force correlation, DPIV

\section{1. はじめに}

建築物の設計では, 風方向荷重, 風直交方向荷重, 据 り風荷重などの各方向成分の組合せを考慮する必要があ り，高層建物については, Melbourne ${ }^{1)}$, Vickery\&Basu ${ }^{2)}$ と Solari\&Pagnini3)などによって検討されている。ちな みに, AS1170.24)では風荷重の組合せについて考慮して いるが，風值交方向の応答が平均值成分を持たず，その 変動成分が風方向の応答より小さい場合は，風方向成分 のみを考虑すれば良いとしている。ASCE7-985)では 60 フィート以上の建物に作用する風荷重の組合せが考慮さ れており，75\%の風方向荷重に，同じ值の風直交方向荷 重を同時に作用させることとして扔り，摸り風荷重につ いても考慮している。ところで, 風方向の変動風力は; 主に接近流の乱れによって発生し, 風直交方向風力と据 りモーメントの変動は渦による影響が支配的である。し たがって, 風直角方向風力と㨝りモーメントの間には強 い相関があるが，風方向風力と他の 2 成分（風直角方向 風力と㹉りモーメント)については相関が殆どないこと が知られている。そのため, 風荷重の組合せを考える場 合, 風直交方向風力と㨝りモーメントの相関は考虑され るが，風方向風力との組合せは無視されがちである。し かし，筆者らは，各風荷重成分の組み合わせを考える上
では,それぞれの絶対値同士の相関を考えるべきであり， 風方向風力と据りモーメント, 風方向風力と風直交方向 風力の間にも, 絶対值同士にはかなり相関があることを 報告している。また, 中低層建物に関しても, 従来のよ うに風方向荷重のみを考えた場合, 柱の最大応力度が 3 割程度も過小評価されることを報告している 6,7)。なお, 風方向風力が最大值をとる瞬間の壁面の風圧分布は, 左 右対称の平均風圧分布とは異なり, 非対称な分布を示し, 据りモーメントも同時に大きな值を示すことなども明ら かにされている。

本報では，低層建物に作用する風力と建物周辺の流れ 場の同時計測を行い，最大抗力発生時など，ある特徴的 なタイミングでの流れ場の性状について考察を行った。

\section{2. 風洞実験}

\section{1 風圧実験}

図 1 に示す正方形平面を有する低㴔建物モデルを用い て, 回流式境界層風洞で風圧測定を行った。風洞実験で 用いた気流は, 図 2 に示す縮尺 $1 / 250$, 平均風速の鉛直 分布べき指数が $\alpha=1 / 6$ である。検討対象とした風向は， 壁面に正対する風向のみである。また，風圧測定点は， 負担面積が等しくなるように壁面に一㥞に配置し，変動 風圧のサンプリング間隔は $\Delta t=1 \mathrm{kHz}$ とした。風圧デ 
ータの導圧チューブの影響は, 予め求めたゲインおよび フェイズ特性を用いて補正した。

建物に作用する変動風圧を空間積分することによって, 風方向風力（抗力） $F_{D}$, 風直交方向風力（揚力） $F_{L}$, 鉛 直方向風力 $F_{T}$, 風方向転倒モーメント $M_{D}$ と風直交方向 転倒モーメント $M_{L}$, および㨝りモーメント $M_{T}$ の各成分 を求め, これらの風力成分を屋根高さの頂部平均速度圧 $q_{H}$ と図 1 に示すディメンジョンを用いて無次元化した。 見付幅を $B$, 奥行きを $D$, 建物高さを $H$ として, 抗力係 数は $C_{D}=F_{D} / q_{H} B H$, 揚力係数は $C_{L}=F_{L} / q_{H} B H$, 㨝りモー メント係数は $C_{T}=M_{T} / q_{H} B H R$ である。ただし, $R$ は平 面の対角線長さの半分, $\left(B^{2}+D^{2}\right) 1 / 2 / 2$ である。

\section{2 流れ場の計測}

建物周辺の流れ場の計測は図 3,4 および表 1 に示す可視 化画像流速計測 DPIV(Dynamic Particle Image Velocimetry)システムを用いて行った。DPIV 計測範囲 は図 5 に示す模型周辺 $(40 \times 50 \mathrm{~cm})$ の領域を $30 \times 22.5 \mathrm{~cm}$ の 4 分割して, サンプリング周波数 $1 \mathrm{k} \mathrm{Hz}, 1$ サンプル 3000 コマで各 10 サンプル (合計 30 秒) の, 風圧力との 流れ場の同時計測を行った。基本風速 $36 \mathrm{~m} / \mathrm{s}$ として 30 秒を実時間に換算するとほほ 50 分間に相当する。圧力 と流れ場の同時測定は図 4 に示す圧力計測システムから トリガー信号を DPIV 用デジタルビデオカメラに送信し て同期を制御している。計測に必要なトレーサー粒子は 模型風下から放出し風洞内を回流させ均一に充満させた。 測定された画像の検査領域単位は $32 \times 32$ pixels として隣 接する検査領域のオーバーラップは $50 \%$ として算定した。

\section{3. 解析結果}

\section{1 壁面に作用する風力, 風圧係数}

図 6 に実時間 10 分のサンプルにおける抗力方向，揚 力方向および据り方向の風力波形の一例を示す。この風 力波形から最大荷重効果（例えば最大抗力係数 $C_{D \max }$ ) と, それが発生した瞬間に同時に発生している他の荷重 効果 (例えば揚力係数 $C_{L}\left(C_{D \max }\right)$, 据りモーメント係数 $\left.C_{T}\left(C_{D \max }\right)\right)$ の組合せを選出して, ○と○で示した。例え ば, 図 6 の最大抗力係数 $C_{D \max }$ が発生した時間 $t_{D}$ におい

Table1 System configuration of DPIV

\begin{tabular}{|c|ll|}
\hline \multicolumn{1}{|c|}{ Equipment name } & \multicolumn{2}{|c|}{ System configuration } \\
\hline \multirow{2}{*}{ High-speed } & Name & : PhantomV7 \\
Digital video camera & Sensor type & : SR-CMOS \\
& Framurat & $:$ 4800frame/s \\
& Number of pixels & $: 800 \times 600$ pixels \\
\hline \multirow{5}{*}{ Double pulse laser } & Name & $:$ Lee Laser \\
& Laser type & $:$ Nd:YAG Laser \\
& Wavelength & $: 532 \mathrm{~nm}$ \\
& Repetition rate & $: 1000 \mathrm{~Hz}$ \\
\hline \multirow{2}{*}{ Particle generator } & Name & $:$ PivPart40 \\
& Particle diameter & $: 1 \mu \mathrm{m}$ \\
\hline
\end{tabular}
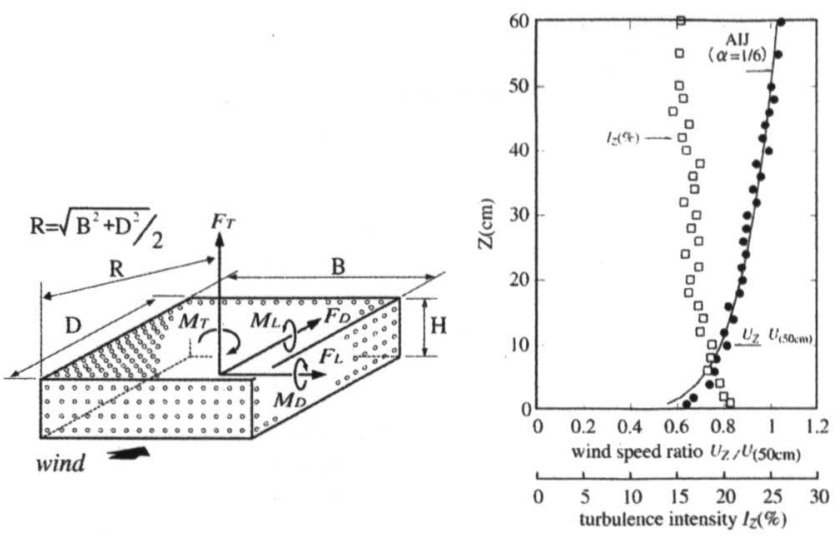

Fig.1 Wind pressure model Fig.2 Approaching flow

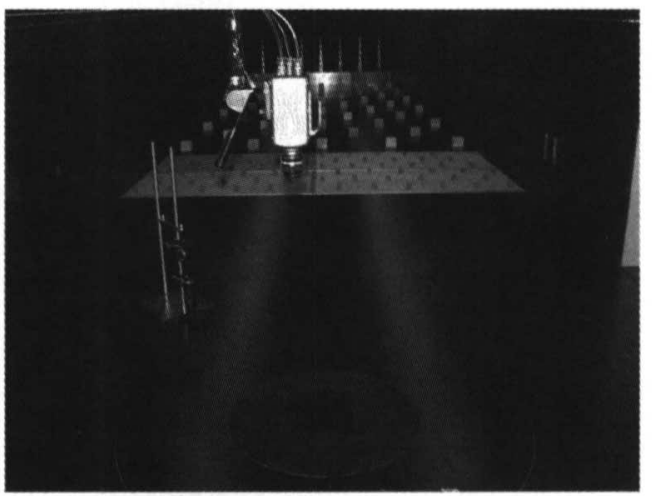

Fig.3 PIV set-up in wind tunnel

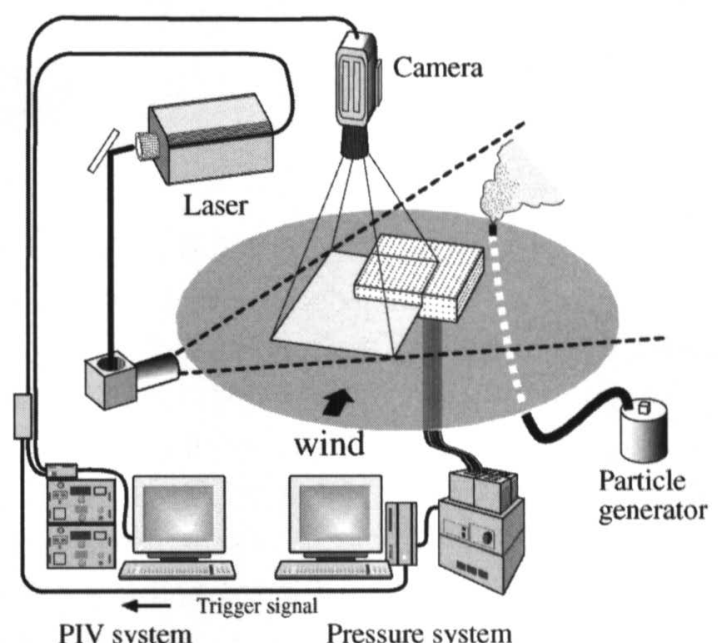

Fig.4 Configuration of PIV system

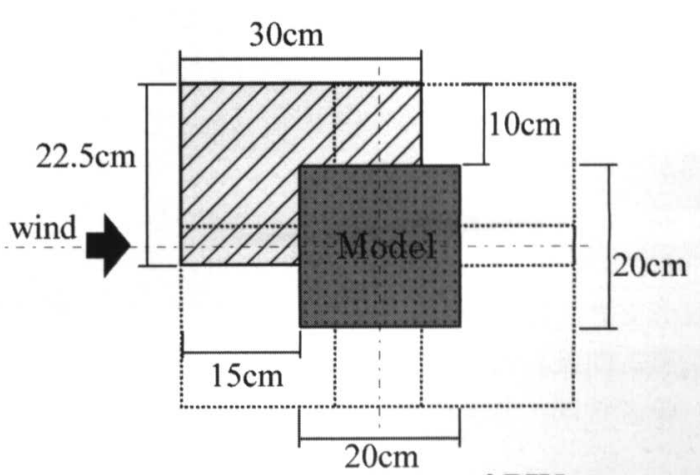

Fig.5 Measurement area of PIV system 
て，ある程度の大きさの揚力係数 $C_{L}\left(C_{D \max }\right)$ が同時に 発生している。最大据りモーメント倸数 $C_{T \max }$ が発生し た時刻 $t_{T}$ では，据りモーメントと一般に高い相関を持つ 揚力係数 $C_{L}\left(C_{T \max }\right)$ は比較的小さな值となっている。 一方, 据りモーメントとの相関が小さい筈の抗力係数 $C_{D}\left(C_{T_{\max }}\right)$ は，その最大值と同程度の高い值が発生し ている。これらの事実は，風力の各成分の最大值同士の 相関は，必ずしも一般の相関係数では説明できず，正負 を無視した絶対值の相関の重要性を示唆している。

図 7 に風力の組合せの位相平面表示の一例を示した。 図 7(a)，(c)は $C_{D}-C_{L}, C_{L}-C_{T}$ の組合せであり，(a)は傾 きの無い楕円形になっており，無相関に近い状態を示し， (c)はやや菱形に近い軸の傾いた楕円形である。一方，図 7(b)の $C_{D}-C_{T}$ は, 原点を頂点とする楔形をして挍り，㨝 り最大時に抗力が最大に近い值をとる傾向が確認できる。 抗力最大時には，据りモーメントは最大から最小のどの ような值でもとり得ることが分かる。

図 8 に各風力成分の最大および最小風力が発生した瞬 間の風圧分布の例を示す。図 8(a)は, 最大抗力 $C_{D \max }$ が 発生した瞬間の風圧分布であり, 図 7(a)の $C_{D}-C_{L}$ の図 中に示した○の位置での瞬間風圧分布である。図 8(a)の 矢印は，この瞬間に同時に発生している据りモーメント の回転方向である。ちなみに，図 8 の結果は実時間換算 10 分間毎の最大值を対象として得られたものであるが，

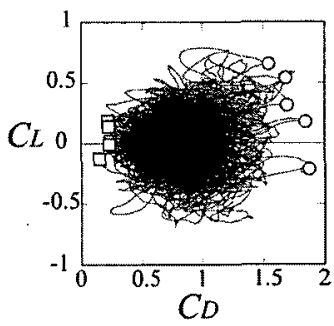

(a) $C_{D}-C_{L}$

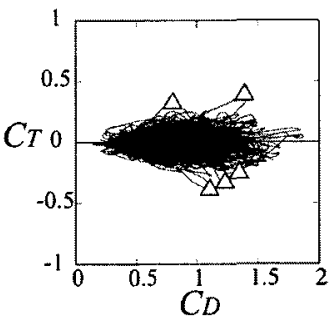

(b) $C_{D}-C_{T}$

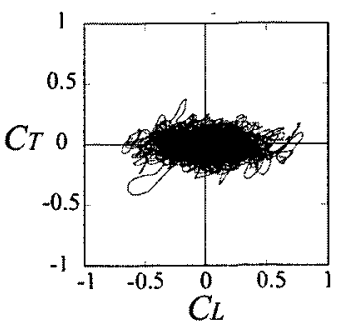

(c) $C_{L} \cdot C_{T}$
図 7 は, 実時間換算 50 分間のデー夕をまとめて示して いる。風上側の壁面に作用する正圧は一様に大きくなっ ている。側面の風圧分布は，据りモーメントの向きに応 じて風上前縁で局所的に大きな負圧が現れている。図 8(b) は最小抗力 $C_{D \min }$ が発生した瞬間の風圧分布（壁面 の風庄分布は, 図 8(a)の 2 倍のスケールで表示している) を示した。これらの分布は図 7(a)の $C_{D}-C_{L}$ の図中に示 した口の位置での瞬間風圧分布である。抗力に寄与する 風上面，風下面での正圧および負圧はともに非常に小さ な值であり，両側面の負圧も小さく，左右ほぼ同程度の 値となっている。図 $8(\mathrm{c})$ は，最大据りモーメント $C_{T_{\max }}$

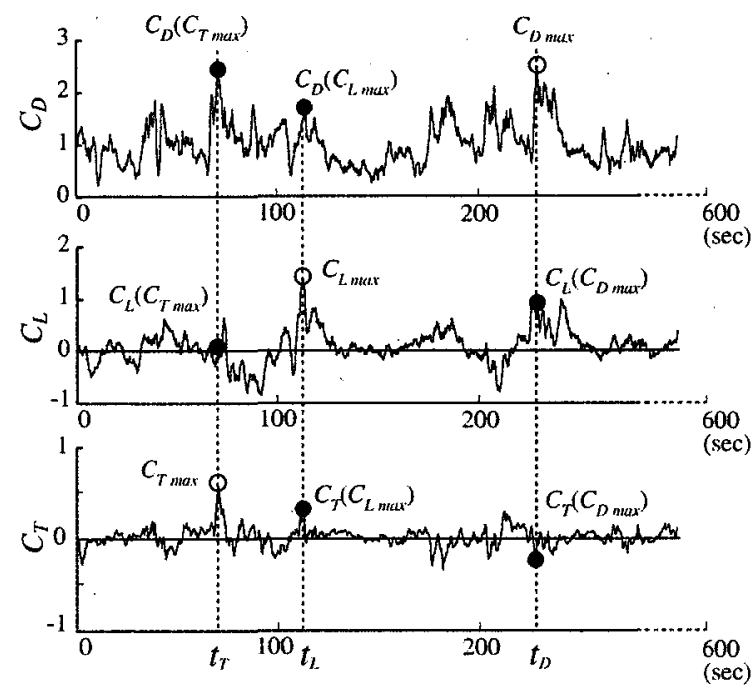

Fig.6. Maximum wind force component $(\mathrm{O})$ and accompanying other wind force components (O)
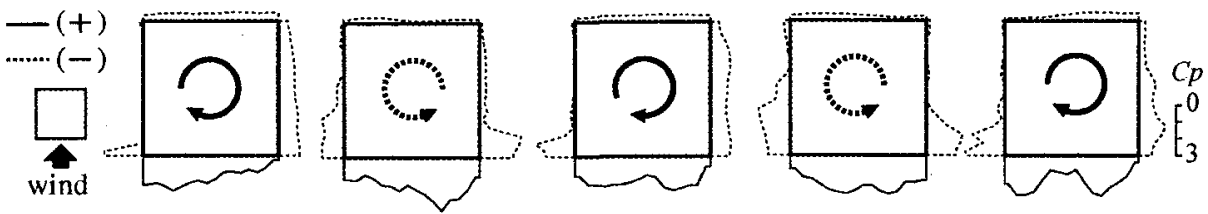

(a) Instances when the maximum along-wind force was observed
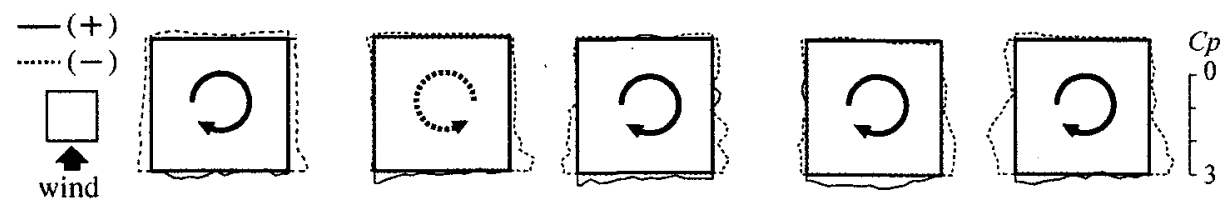

(b) Instances when the minimum along-wind force was observed.
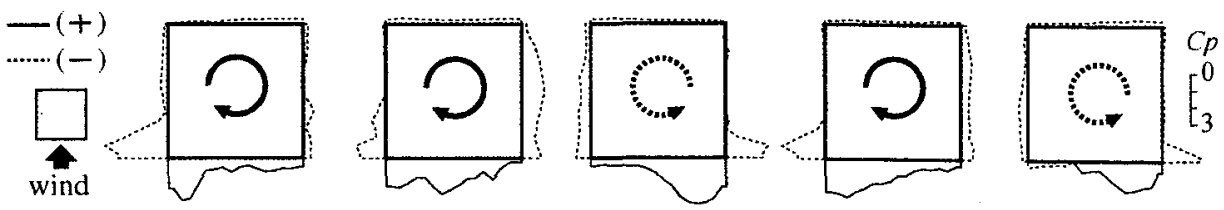

(c)Instances when the maximum torsional moment was observed

Fig.7 Phase-plane expression Fig.8 Instantaneous wind pressure distributions causing of wind force combination maximum/minimum wind force components $(5 / 8) \mathrm{H}$ 
が発生した瞬間の風圧分布の例であり, 図 7(b)の $C_{D}-C_{T}$ の図中に示した $\triangle の$ 位置での瞬間風圧分布である。風上 側壁面の風圧分布は一方に傾き，側面でも㨝りモーメン トの向きに応じて風上前縁で局所的に大きな負圧が発生 し, 図 8(a)の最大抗力発生時の分布と類似している。

\section{2 建物周辺の流れ場}

図 9 にDPIV システムで測定した流れ場を示しており, 図 5 で示した各領域別に同時測定された流れ場と壁面風 压を用いて各風力成分の最大あるいは最小の值が発生し た瞬間の流れ場を据りモーメントの符号を適合させてア ンサンブル平均（実時間 10 分間相当 5 サンプル）した。 図 9(a) は最大抗力が発生した瞬間の流れ場である。壁面 の風压分布は図 8(a)に示した瞬間風圧分布を全デー夕に 関してアンサンプル平均（実時間 10 分間相当 20 サンプ ル）したものである。流れは前縁の隅角部から剥離して 抢り, 左側（上）では風上側前方で再付着し，負圧も大 きくなっている。右側（下）では，側面後方まで渦が移 流した影響で負圧の領域が後方まで広がっている。図 9(b)は最小抗力が発生した瞬間の流れ場である。建物周 辺の流れ場は概ね左右対称となっており, 図 9(a)と比較 して風上側の風速が全体的に小さな值となっている。図 9(c)に最大搌りモーメントが発生した瞬間の流れ場を示 す。風上側の流れ場はやや左側（上）に傾いているおり， 隅角部から流れが剥離する様子が明確で, 壁面でも大き な負圧が発生している。また, 流れ場が再付着する付近 で圧力が回復している様子が観察できる。

\section{4. まとめ}

低層建物に作用する風圧力と流速場の同時計測を行った。 その結果, 最大/最小風力発生時の風庄分布と流机場の 性状, 特に風力が非常に減少する建物まわりの流れ場の 性状を確認することができた。また，壁面風圧係数分布 やDPIV を用いた流速場の測定結果の比較がなされ, 雨者 の対応が確認された。

\section{参考文献}

1) Melbourne, W.H. (1975), Probability distributions of response of BHP house to wind action and model comparisons. J. of Industrial Aerodynamics 1:2, 167-175

2) Vickery, B.J. and Basu, R.I. (1984), The response of reinforced concrete chimneys to vortex shedding. Engineering Structures, 6, 324-333.

3) Solari, G. and Pagnini, L.C. (1999). Gust buffeting and aeroelastic behaviour of poles and monotubular towers. J. of Fluid and Structures 13, 877-905.

4) AS 1170.2-1989. (1989). The Australian Wind Loading Standard. SAA

5) ASCE 7-98. (2000). Minimum Design Loads for
Buildings and Other Structures. ASCE

6) Tamura, Y., Kikuchi, H. and Hibi, K. :"Wind load combinations and extreme pressure distributions on low-rise buildings", Wind and Structures, An International Journal, 3:4, 279-289,2000

7）㐘池浩利, 田村幸雄, 日比一喜：“低層建物の風荷重の組 合せに関する研究”, 日本建築学会構造系論文集, 第 551 号, pp. $13-20,2002$ 年

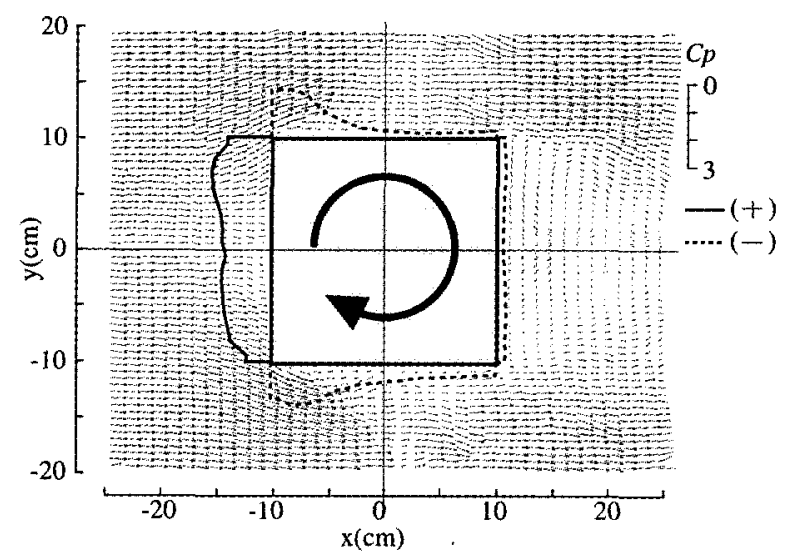

(a) Instance when maximum along-wind force was observed

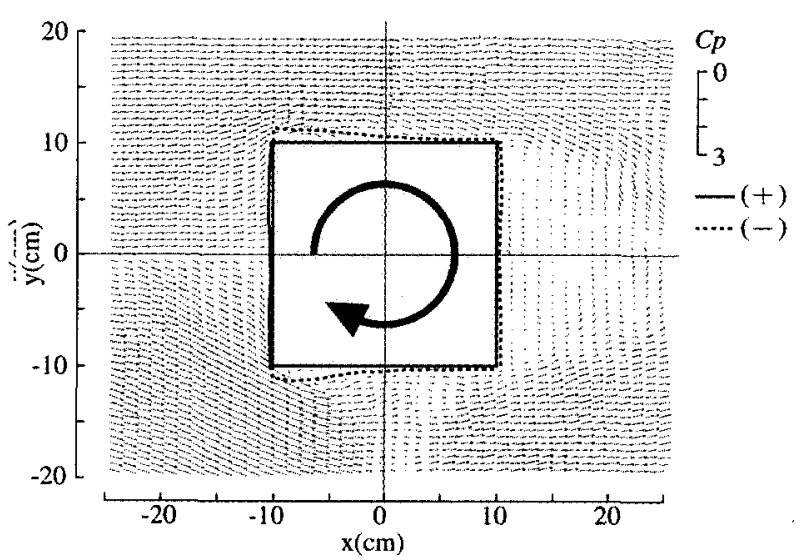

(b) Instance when minimum along-wind force was observed

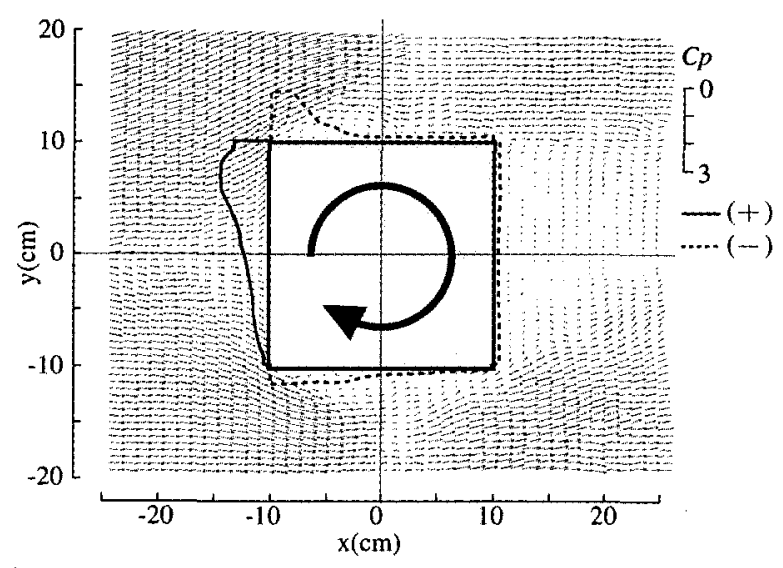

(c) Instance when maximum torsional moment was observed

Fig.9 Ensemble-averaged instantaneous wind pressure distributions and flow fields causing maximum/minimum wind force components 